\title{
LA DATACIÓN RADIOCARBÓNICA DE TABLETAS Y TUBOS DE INHALACIÓN DE LA PAYA (NOROESTE ARGENTINO) Y SU INTEGRACIÓN A OTROS ANÁLISIS ESPECÍFICOS
}

\author{
Marina Sprovieri
}

\begin{abstract}
Este trabajo integra los datos de una serie de análisis realizados sobre tabletas y tubos procedentes del sitio de La Paya en el Valle Calchaquí, en el Noroeste argentino. Se pone énfasis en los fechados radiocarbónicos y datos contextuales, buscando completar y enriquecer nuestra información sobre la procedencia de las maderas y sobre la vinculación estilística con otras regiones. Los resultados de los fechados, junto con la información contextual, señalan que los artefactos para inhalación de alucinógenos se asocian más fuertemente al período de Desarrollos Regionales en el Valle Calchaquí, con escasa vinculación a contextos Inkaicos. Esto indicaría que los circuitos que permitieron el aprovisionamiento de maderas de otras regiones para algunas de las tabletas y tubos calchaquíes se encontraban vigentes para dicho período. Lo mismo sucedía para aquella esfera por la que circuló información estilística relativa a tabletas y tubos, que abarcó las áreas del Valle Calchaquí, la puna de Jujuy, la Quebrada de Humahuaca y la región del Río Loa.
\end{abstract}

This work integrates data from several analyses performed on snuff trays and tubes from La Paya in the Calchaquí Valley, Northwestern Argentina, to provide new insights on wood provenance and stylistic influences from other regions during the Regional Development and Inka periods. We use radiocarbon dating and contextual information to show that snuff trays and tubes are more strongly associated with the Regional Development Period (AD 900-1430/1470) in the Calchaquí Valley, with limited correlation to Inka contexts. This also implies the existence of networks that facilitated the procurement of wood from other regions (Subandean Region or Yungas) to make some Calchaqui snuff trays and tubes. There were also networks encompassing areas of the Calchaquí Valley, the Puna of Jujuy, the Quebrada de Humahuaca, and the Loa River region, through which stylistic information circulated.

\section{Tabletas y Tubos de Inhalación de Alucinógenos en el Noroeste Argentino}

$\mathrm{E}$ ntre las primeras colecciones arqueológicas del Noroeste argentino (NOA) a comienzos del siglo pasado se encontraban tabletas y tubos para inhalar alucinógenos (Figura Suplementaria 1), los cuales fueron estudiados desde perspectivas estilísticas principalmente. Su cronología ha sido establecida por asociación a materiales temporalmente diagnósticos, siendo hoy muy pocos los casos de tabletas y tubos datados directamente en los Andes del Sur (Richardin et al. 2015).

Aquí se integran los datos poco conocidos sobre una serie de análisis realizados en tabletas y tubos de una región del NOA, con énfasis en aquellos provenientes de dataciones directas y contextos de hallazgo. Se busca aportar datos cronológicos específicos que completen y enriquezcan la información que obtuvimos de la identificación de las maderas usadas para su confección y de su vinculación estilística con otras regiones del NOA y el norte de Chile.

\section{La Colección de Tabletas y Tubos de La Paya}

En el NOA, los vestigios de tabletas y tubos son limitados, destacándose por número e integridad los de la colección del sitio de La Paya (Valle Calchaquí, provincia de Salta), una de las pocas con este tipo de hallazgos de los valles mesotermales del NOA (Figura 1). La Paya es

Marina Sprovieri a CONICET - UNLP. División Arqueología, Facultad de Ciencias Naturales y Museo, Universidad Nacional de La Plata. Anexo Museo, Av. 122 y 60, Laboratorio 102, (1900), La Plata, Argentina (msprovieri@fcnym.unlp.edu.ar)

Latin American Antiquity, page 1 of 6

Copyright $@ 2017$ by the Society for American Archaeology doi:10.1017/laq.2017.58 


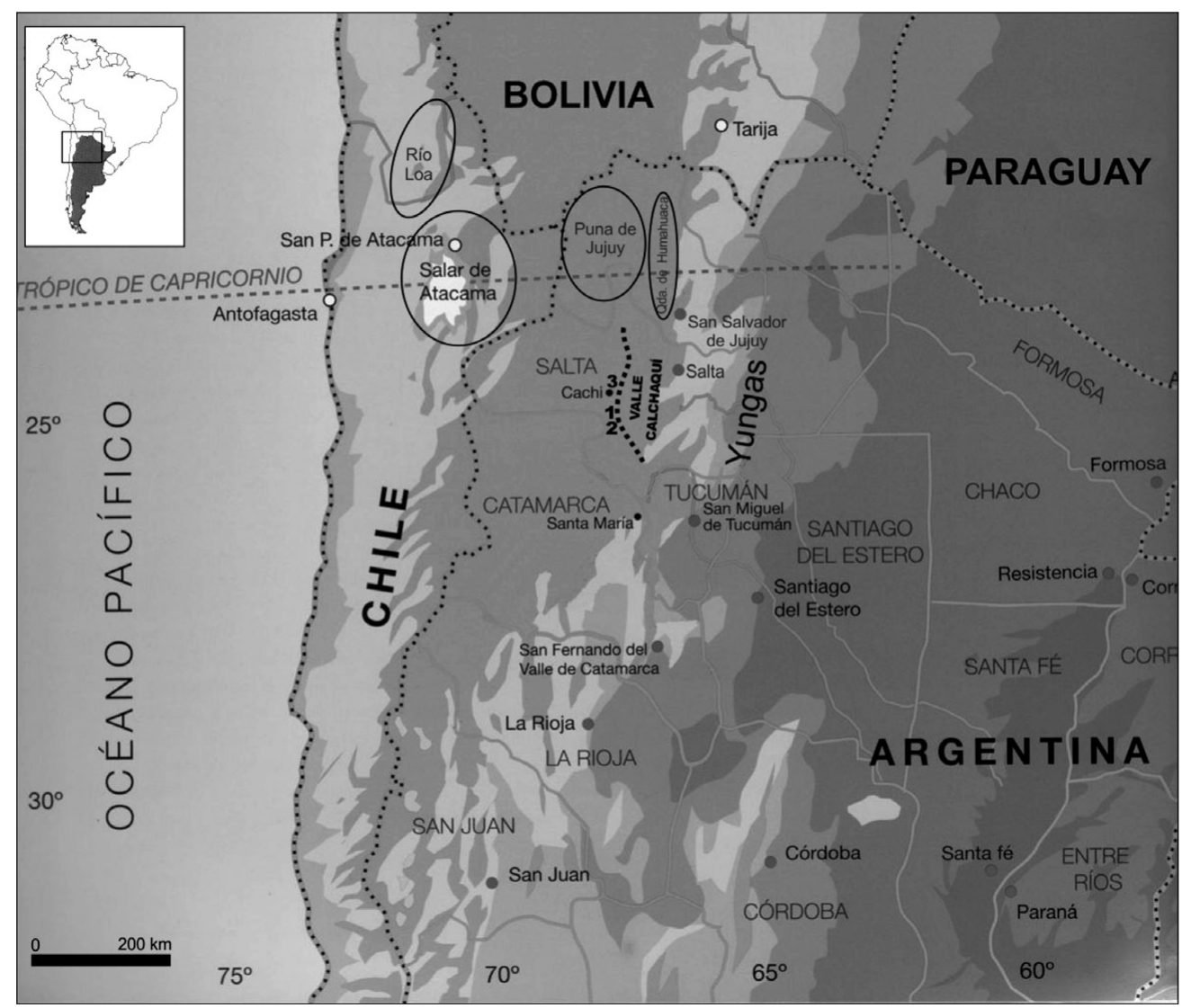

Figura 1. Mapa del NOA con localización de las regiones, sitios y localidades mencionados: (1) La Paya; (2) El Churcal; (3) Tero y Fuerte Alto (modificado de Goretti [2006:15]).

un asentamiento conglomerado del período de Desarrollos Regionales (PDR; 900-1430/1470 dC) con evidencias de ocupación durante el período Inka $(1430 / 1470-1536 \mathrm{dC})^{1}$.

A principios del siglo $\mathrm{XX}$, las excavaciones de 200 contextos funerarios (Ambrosetti 1907) y las compras a pobladores locales de Ambrosetti (1907) y Boman (1908) permitieron conformar una colección de más de 1.500 objetos. En ella se destaca la alta conservación de objetos en madera, entre los cuales había originalmente 18 tabletas y 18 tubos de inhalación, como parte del ajuar de 18 entierros. Estos ejemplares fueron estudiados tempranamente por Ambrosetti (1907) y luego por Torres $(1986,1987,1998)$.

$\mathrm{Si}$ bien con posterioridad se sucedieron nuevas propuestas clasificatorias y estudios de tabletas y tubos surandinos, los artefactos de inhalación de La Paya, u otros del Valle
Calchaquí, no habían vuelto a ser estudiados puntualmente. En 2005 encaramos un nuevo análisis de estos artefactos como parte de un estudio mayor sobre los procesos de circulación interregional de bienes e ideas en el Valle Calchaquí entre los siglos X y XVI (Sprovieri 2010), considerando que formaban un conjunto con información potencial y que requería de análisis más profundos.

Reunimos 50 ejemplares de tabletas y tubos del Valle Calchaquí, mayormente de La Paya, pero también algunos de otros sitios o localidades de la región (Tabla Suplementaria 1 y Figura 1). Se contó en la mayoría de los casos con posibilidades de análisis directo de las piezas en el Museo Etnográfico J. B. Ambrosetti de Buenos Aires, el Museo E. Casanova de Tilcara de Jujuy y el Museo Arqueológico P. P. Díaz de Cachi de Salta, mientras que para aquellos 
ejemplares faltantes en la actualidad se recurrió a información bibliográfica.

A partir de esto, desarrollamos primero un análisis morfológico e iconográfico para caracterizar este conjunto y agrupar los artefactos de acuerdo a rasgos comunes. Posteriormente, realizamos un análisis comparativo que mostró que las piezas calchaquíes presentan estrechas semejanzas con piezas de la puna de Jujuy y la Quebrada de Humahuaca en Argentina y de la región del Río Loa en Chile, aunque no tan claras con las de San Pedro de Atacama (Figura 1; Sprovieri 2009).

Paralelamente a los análisis estilísticos, realizamos un acercamiento a la identificación de las maderas que fueron utilizadas para confeccionar cinco tabletas y cuatro tubos de La Paya y de Cachi. Por pertenecer las piezas a una colección de museo, las posibilidades de intervención son limitadas, por lo que se logró separarlas en grupos con características anatómicas similares y correlacionarlos con maderas nativas afines. Los resultados mostraron el empleo de cuatro maderas como materia prima: Prosopis sp., Bulnesia sp. o Larrea sp., Acacia sp. y Anandenanthera colubrina. Tres de ellas tienen disponibilidad local, mientras que A. colubrina se desarrolla en las Yungas, al este del Valle Calchaquí (Figura 1). Esto señalaría la existencia de circuitos por los que se dio el aprovisionamiento y uso de madera no local para artefactos del Valle Calchaquí (Sprovieri 2010; Sprovieri y Rivera 2014). Estos análisis estilísticos y de procedencia de piezas calchaquíes pueden vincularse con aquellos que se vienen desarrollando para otras regiones del NOA y el norte de Chile (Texto Suplementario 1).

\section{Datación Radiocarbónica e Información Contextual de Tabletas y Tubos de La Paya}

Realizamos fechados radiocarbónicos por AMS de una tableta y de un tubo de madera de La Paya depositados en el Museo Etnográfico (Figura 2 y Texto Suplementario 2). Este método resulta adecuado para piezas de museo debido a la necesidad de una muestra reducida de material, por lo que la intervención es mínima. Las dataciones fueron realizadas en el NSF-Arizona AMS Laboratory en Tucson. Los fechados señalan una cronología similar para ambas piezas correspondiente al siglo XIV (Tabla Suplementaria 2), lo que las ubica dentro del PDR (Sprovieri 2010).

No se contaba hasta el momento con un registro y análisis detallado de las condiciones de hallazgo y asociaciones de tabletas y tubos del Valle Calchaquí desde perspectivas arqueológicas actuales. Nuestro relevamiento sistemático e integral de la colección completa de La Paya existente en museos de Argentina y del exterior permite hoy contar con esa información e incorporarla a un análisis integral de estos objetos (Sprovieri 2010).

Los artefactos para inhalación de La Paya provienen de 18 contextos funerarios ${ }^{2}$. Se trata de tumbas de paredes de piedra de forma circular y una de forma rectangular, dentro de las cuales fueron inhumados entre uno y 10 individuos, mayormente adultos. Acompañando los cuerpos se depositó una cantidad variable de objetos de diversos tipos y materia prima a modo de ajuar.

Logramos el análisis directo de un $38,5 \%$ $(N=304)$ de los objetos que componen el ajuar de estas tumbas y de los restantes mediante imágenes y descripciones bibliográficas (Ambrosetti 1907). Podemos sostener que, de estos 18 contextos, sólo uno (la tumba $\mathrm{N}^{\circ}$ 161) presenta claras vinculaciones a la época Inka por la presencia de cinco vasijas de tipo Inka Provincial e Inka Mixto, mientras que los restantes materiales presentan características morfo-estilísticas que se corresponden con tradiciones locales de manufactura (Sprovieri 2010). Las dataciones radiocarbónicas y la información contextual parecieran apuntar a que las prácticas de inhalación de alucinógenos fueron un fenómeno que, en el Valle Calchaquí, se manifestó con mayor frecuencia durante el PDR.

En otras zonas del NOA, los artefactos de inhalación aparecen en contextos fechados entre 1297 y 1436 dC (Fernández Distel 2001; Horta Tricallotis 2012; Montenegro 2004), con algún caso de asociación a contextos Inkas (Horta Tricallotis 2012; Salas 1945). Por su parte, en el norte de Chile la inhalación de alucinógenos se manifiesta desde al menos $400 \mathrm{dC}$; sin embargo, los estilos de tabletas y tubos que se vinculan con el NOA tienen un desarrollo posterior. El estilo Circumpuneño ha sido relacionado principalmente al período Intermedio tardío 


\section{Tableta N01129}
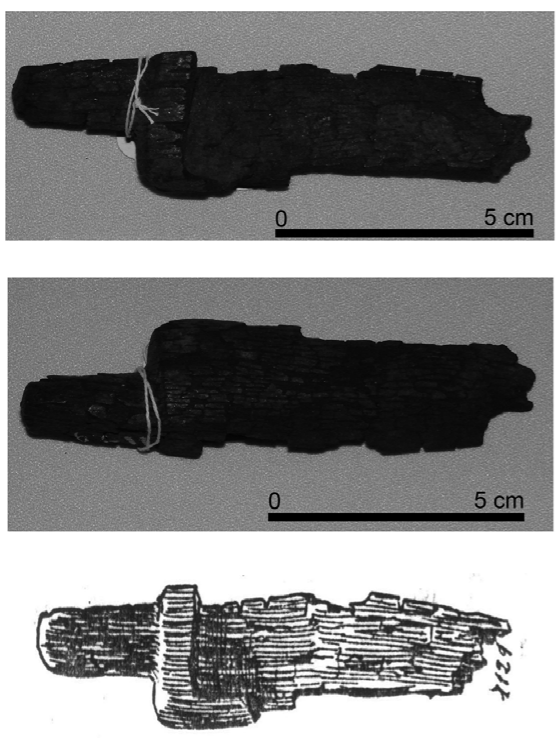

Tubo No 1141

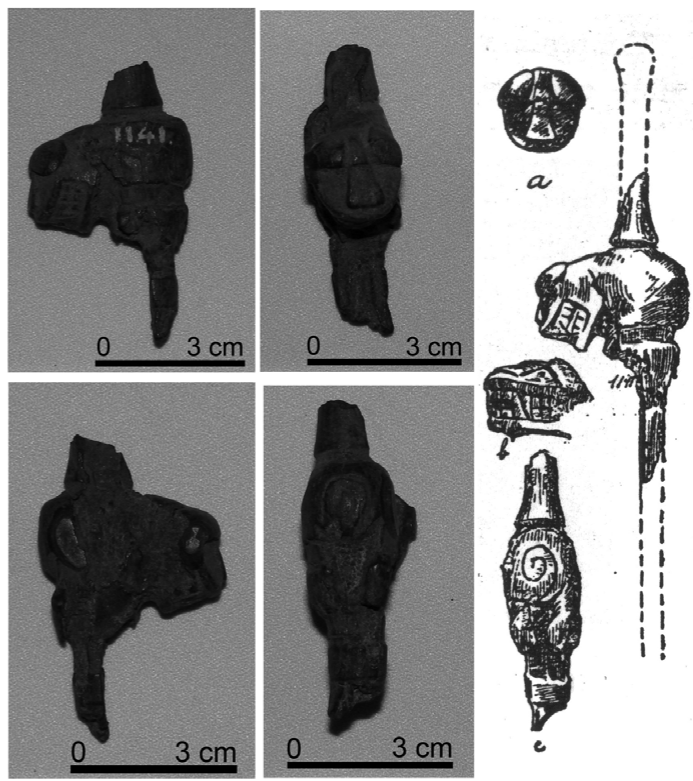

Figura 2 . Tableta y tubo fechados de La Paya (Ambrosetti 1907:Figuras 88 y 100).

(Horta Tricallotis 2012; Horta Tricallotis et al. 2016), mientras que el Atacameño tendría vigencia durante ese mismo período e incluso bajo la dominación Inka, con una probable supervivencia en época colonial (Horta Tricallotis et al. 2016). Recientemente, Richardin et al. (2015) realizaron las primeras dataciones radiocarbónicas sobre ocho tabletas de Atacama, que arrojaron fechados que abarcan desde el período Medio al Intermedio tardío (entre 300 y $1400 \mathrm{dC}$ ). Dos tabletas que corresponden al estilo Circumpuneño mostraron fechados de 8921016 cal dC y 1299-1399 cal dC (2o); ningún ejemplar del estilo Atacameño fue fechado en esa oportunidad (Richardin et al. 2015).

\section{Comentarios Finales}

El hallazgo de tabletas y tubos de inhalación en el NOA es sumamente limitado, por lo que el análisis profundo e integral de los conjuntos existentes, como el de La Paya, es imprescindible. La integración de datos aquí presentada sobre 50 tabletas y tubos del Valle Calchaquí ha permitido generar información de relevancia sobre estos artefactos y prácticas asociadas a nivel regional y con alcance a escala surandina.
Por una parte, la información cronológica absoluta y contextual señala que en el Valle Calchaquí los artefactos para inhalación de alucinógenos se asocian más fuertemente al PDR, con una vinculación más limitada a contextos de época Inka en la región. Si bien existen evidencias claras de la perduración de las prácticas inhalatorias en el tiempo en la región surandina, cabe preguntarse si no habrá existido una disminución o menor visibilidad en las mismas, posiblemente vinculada con cambios en el ceremonialismo y las prácticas rituales introducidos por los Inkas en los territorios anexados (D'Altroy et al. 2000; Nielsen 2007).

Por otra parte, en términos de consumo y circulación interregional de materias primas, los resultados cronológicos indicarían que los circuitos por los que ingresaron al Valle Calchaquí recursos madereros de las Yungas estarían vigentes desde el PDR. Esta situación es evidenciada también por la presencia de frutos de nogal y otras maderas (lianas y nogal criollo; Sprovieri 2010; Sprovieri y Rivera 2014).

Finalmente, antes sólo contábamos con una datación relativa para las semejanzas morfológicas e iconográficas detectadas entre ejemplares del Valle Calchaquí y de otras regiones, 
permaneciendo asociadas a un lapso temporal amplio que abarcaba los siglos X a XVI. Ahora contamos con mayores elementos que permiten vincularlas más estrechamente al PDR, evidenciando que el Valle Calchaquí estaría inserto en una esfera de circulación macrorregional de información estilística desde esos momentos.

La información cronológica generada para tabletas y tubos del Valle Calchaquí permitió ajustar temporalmente los procesos de circulación interregional de maderas y de estilos en los que se vieron insertas las poblaciones calchaquíes. Considerando esto en relación con los resultados mencionados anteriormente que se vienen obteniendo para otras regiones del NOA y el norte de Chile, podemos preguntarnos si este fenómeno de circulación macrorregional de información estilística no estaría imbricado con los circuitos de aprovisionamiento de maderas para la confección de tabletas y tubos.

El área atacameña y la puna argentina tienen una muy limitada disponibilidad de recursos madereros. Esto plantea la necesidad de obtención de maderas de otras regiones ecológicas, como lo confirman los últimos estudios que proponen como posibles zonas de procedencia los bosques húmedos y de altura del NOA y Bolivia (Niemeyer 2013; Riquelme 2012; Riquelme y Niemeyer 2015). Es posible pensar que los circuitos por los que se movilizaron maderas entre estas zonas se vieron entrelazados o coincidieron con aquellos por los que circularon estilos en tabletas y tubos. Esta circulación macrorregional entre el norte de Chile (Atacama y Loa) y el NOA (puna de Jujuy, Quebrada de Humahuaca y Valle Calchaquí) ocurría al mismo tiempo que en otros aspectos se conformaban estilos a escala más pequeña, de fuerte unidad formal e iconográfica al interior de cada una de estas regiones, por ejemplo en la alfarería y la metalurgia (Sprovieri 2016).

Consideramos que la integración de datos aquí presentada muestra el potencial de los análisis específicos de conjuntos particulares de artefactos, que en este caso permitieron obtener información ajustada y novedosa sobre piezas recuperadas hace más de un siglo. A su vez, esto plantea la necesidad de extender las dataciones radiocarbónicas absolutas en tabletas y tubos de inhalación de alucinógenos de la región suran- dina en general para una comprensión integral del fenómeno.

Agradecimientos. Al Dr. A. J. Timothy Jull, Director del NSF-Arizona AMS Laboratory, por la realización de los fechados por AMS. A las autoridades y personal del Museo Etnográfico J. B. Ambrosetti, del Museo E. Casanova y del Museo Arqueológico P. P. Díaz por permitir el análisis de los materiales. A la Dra. M. Montenegro por compartir su tesis inédita. Esta investigación fue posible gracias a una beca doctoral del Consejo Nacional de Investigaciones Científicas y Técnicas de la República Argentina (CONICET) y a subsidios del CONICET y la Universidad Nacional de La Plata (UNLP).

Declaración de Disponibilidad de Datos. Las piezas estudiadas se encuentran depositadas en el Museo Etnográfico J. B. Ambrosetti, el Museo E. Casanova y el Museo Arqueológico P. P. Díaz.

Materiales Suplementarios. Para acceder a los materiales suplementarios que acompañan este artículo visitar: https:// doi.org/10.1017/laq.2017.58.

Texto Suplementario 1. Los Análisis de Tabletas y Tubos de Inhalación de La Paya en el Contexto Surandino.

Texto Suplementario 2. Los artefactos de Inhalación Fechados de La Paya.

Figura Suplementaria 1. Tubo y tableta.

Tabla Suplementaria 1. Cantidad de Piezas Consideradas del Valle Calchaquí.

Tabla Suplementaria 2. Fechados radiocarbónicos de piezas de La Paya.

\section{Referencias Citadas}

Ambrosetti, Juan B.

1907 Exploraciones arqueológicas en la ciudad prehistórica de La Paya (Valle Calchaquí, Pcia. de Salta). Revista de la Universidad de Buenos Aires VIII:5-534.

Boman, Eric

1908 Antiquités de la Región Andine de la République Argentine et $d u$ Désert D’Atacama. Imprimerie Nationale, París.

D’Altroy, Terence, Ana M. Lorandi, Verónica Williams, Milena Calderari, Christine Hastorf, Elizabeth DeMarrais y Melissa Hagstrum

2000 Inka Rule in the Northern Calchaquí Valley, Argentina. Journal of Field Archaeology 27:1-26.

Fernández Distel, Alicia A.

2001 Dos nuevas tabletas de rapé para la región Humahuaca. Ponencia presentada en el Tercer Encuentro Internacional Humboldt, Salta, Argentina.

Horta Tricallotis, Helena

2012 El estilo Circumpuneño en el arte de la parafernalia alucinógena prehispánica (Atacama y Noroeste argentino). Estudios Atacameños 43:5-34.

Horta Tricallotis, Helena, Jorge Hidalgo Lehuedé y Valentina Figueroa Larre

2016 Transformación y resignificación de la parafernalia alucinógena prehispánica en Atacama a la luz de un documento del siglo XVII. Estudios Atacameños 53:93116. 
Montenegro, Mónica

2004 Los caminos del Complejo Alucinógeno: Analogías entre las tabletas para uso de sustancias psicoactivas del norte de Chile y Noroeste argentino durante el período de Desarrollos Regionales. Tesis de maestría, Instituto de Investigaciones Arqueológicas y Museo, Universidad Católica del Norte, Antofagasta, Chile.

Goretti, Matteo (editor y compilador)

2006 Tesoros precolombinos del Noroeste argentino. Museo de Arte Hispanoamericano I. Fernández Blanco, Fundación CEPPA, Buenos Aires.

Nielsen, Axel E.

2007 Celebrando con los antepasados. Arqueología del espacio público en Los Amarillos, Quebrada de Humahuaca, Jujuy, Argentina. Mallku Ediciones, Buenos Aires.

Niemeyer, Hermann M.

2013 On the Provenience of Wood Used in the Manufacture of Snuff Trays from San Pedro de Atacama (Northern Chile). Journal of Archaeological Science 40:398-404.

Richardin, Pascale, Catherine Lavier, Helena Horta, Valentina Figueroa y Nicolás Lira

2015 Radiocarbon Dating Of Atacama (Chile) Snuff Trays: An Update on Stylistic and Chronological Correlations. Radiocarbon 57(5):775-784.

Riquelme, Isabella

2012 Tabletas del complejo psicotrópico de San Pedro de Atacama: Nuevas perspectivas de interacción humana desde el análisis de anatomía de la madera. Tesis de licenciatura, Facultad del Patrimonio, Universidad Internacional SEK, Santiago, Chile.

Riquelme, Isabella y Hermann M. Niemeyer

2015 Tabletas del complejo psicotrópico de San Pedro de Atacama: Nuevas perspectivas desde el análisis anatómico de la madera. En El Horizonte Medio: Nuevos aportes para el sur de Perú, norte de Chile y Bolivia, editado por Anti Korpisaari y Juan Chacama, pp. 291-305, Instituto Francés de Estudios Andinos y Universidad de Tarapacá, Chile.

Salas, Alberto M.

1945 El antigal de Ciénaga Grande (Quebrada de Purmamarca, Prov. de Jujuy). Publicaciones del Museo Etnográfico, Serie A, Vol. 5. Universidad Buenos Aires, Buenos Aires.
Sprovieri, Marina

2009 Alucinaciones en circulación. Una mirada a la interacción surandina tardía desde las tabletas y tubos de La Paya (Valle Calchaquí, Salta). Anales del Instituto de Arqueología y Etnología $\mathrm{N}^{\circ}$ 63-64:81-105.

2010 El mundo en movimiento: Circulación de bienes, recursos e ideas en el Valle Calchaquí (Salta). Una visión desde La Paya. Tesis doctoral, Facultad de Filosofía y Letras, Universidad de Buenos Aires, Buenos Aires.

2016 Materialidades, movimientos y articulaciones interregionales en el Valle Calchaquí (Salta, Noroeste argentino) durante el período de Desarrollos Regionales. Actas del XIX Congreso Nacional de Arqueología Argentina, Serie Monográfica y Didáctica Vol. 54, pp. 1814-1818. Facultad de Ciencias Naturales, Universidad Nacional de Tucumán, Argentina.

Sprovieri, Marina y Stella Maris Rivera

2014 Las maderas de la "Colección La Paya". Circulación y consumo en el Valle Calchaquí (Salta). Intersecciones en Antropología 15(1):89-102.

Torres, Constantino M.

1986 Tabletas para alucinógenos en Sudamérica: Tipología, distribución y rutas de difusión. Boletín del Museo de Arte Precolombino 1:37-53.

1987 The Iconography of South American Snuff Trays and Related Paraphernalia. Etnologiska Studier 37:1134.

1998 Psychoactive Substances in the Archaeology of Northern Chile and NW Argentina: A Comparative Review of the Evidence. Chungara 30(1):49-63.

\section{Notas}

1. El período de Desarrollos Regionales se corresponde con el lapso que en los Andes meridionales se identifica como período Intermedio Tardío y el período Inka con el horizonte Tardío.

2. Tumbas $\mathrm{N}^{\circ} 19,21,33,40,41,88,88 \mathrm{a}, 96,121,126$, $130,131,132,144,158,161,164$ y 189.

Submitted December 21, 2016; Revised July 12, 2017;

Accepted September 13, 2017 